\title{
What is the best approach for surgery of malignant pleural mesothelioma? It is to put our efforts into obtaining trustworthy evidence for practice
}

\author{
Tom Treasure, MD, MS, FRCS, FRCP
}

\author{
From the Clinical Operational Research Unit, University College London, London, United Kingdom. \\ Disclosures: Author has nothing to disclose with regard to commercial support. \\ Received for publication Sept 2, 2015; accepted for publication Sept 22, 2015; available ahead of print \\ Oct 27, 2015. \\ Address for reprints: Tom Treasure, MD, MS, FRCS, FRCP, Clinical Operational Research Unit, University Col- \\ lege London, 4 Taviton St, London WC1H 0BT, United Kingdom (E-mail: tom.treasure@ gmail.com). \\ J Thorac Cardiovasc Surg 2016;151:307-9 \\ $0022-5223 / \$ 36.00$ \\ Copyright (C) 2016 by The American Association for Thoracic Surgery \\ http://dx.doi.org/10.1016/j.jtcvs.2015.09.086
}

Under the banner "Statistics for the Rest of Us," the Journal in 2007 published a critique of case series reports to determine whether surgical resection is effective in improving survival for patients with malignant pleural mesothelioma. ${ }^{1}$ The article concluded, "We owe it to today's patients with mesothelioma to get it right. The epidemic is still rising in Europe and there will be many patients in the next 10 to 20 years. We owe it to the rest of the world where asbestos was less well controlled or remains uncontrolled. Equally important is this: we owe it to our own scientific integrity."

There have been some randomized controlled trials, ${ }^{2-4}$ but it looks like business as usual-more uncontrolled case series with their inherent limitations.

The criteria for observational data to be accepted as evidence have been well described: when an intervention visibly, quickly, and reproducibly alters the course of a disease, cause and effect may be accepted as evident. ${ }^{5,6}$ Tension pneumothorax, empyema, cataract, hip fracture, leaking aneurysm, and aortic stenosis are familiar examples. Surgery for mesothelioma meets none of the criteria for acceptance on experience alone. Surgery is performed neither to avert imminent death nor for immediate benefit, nor is cure evident. ${ }^{7}$ There are too many biologic and therapeutic variables to determine whether in truth death is delayed; it may even be hastened. Heterogeneity in the progression of the disease provides some patients who naturally survive long without operation, so in the absence of fair comparators it is not possible to confidently attribute the life of any individual patient with mesothelioma to an operation done a year or two previously.

At the very least, we should have better estimates of what would be the expected survival of patients, comparable with those operated on, if cared for without surgery. Reports of surgical series have been presaged with gloomy statements that survival is likely to be as short as " 4 to 12 months," but

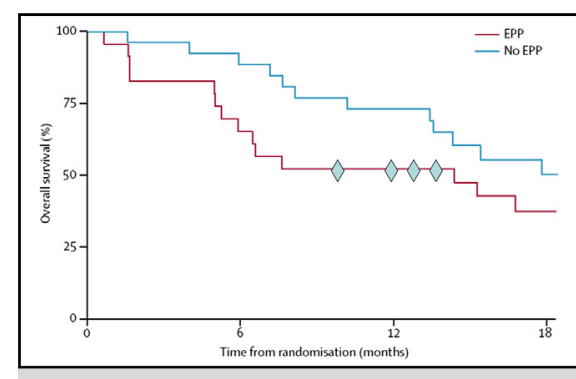

Published survival with EPP matched MARS; random assignment to no EPP resulted in better outcomes. The diamonds represent references 1 through 4.

\section{Central Message}

Better evidence is required, and randomized trials are necessary, in malignant pleural mesothelioma.

See Articles page 468 and 478.

See Editorial Commentaries page 476 and 485 .

such statements set the bar too low. Patients with an outlook as poor as that are not the ones who have been operated on. Estimates of what would have been survival without surgery are difficult to obtain, but without appropriate control data we cannot know what difference surgery makes to survival. Patients eligible for extrapleural pneumonectomy (EPP) within the Mesothelioma and Radical Surgery protocol but randomly assigned not to undergo EPP survived a median of 19.5 months, ${ }^{2}$ and that is a longer survival than in reported EPP series in the same epoch. ${ }^{4,8-10}$

Statistical analysis of existing data has not resolved the doubt about effectiveness of surgery. In a cancer registry, the purported survival difference for EPP dwindled to insignificance when a simple correction was made by excluding from comparison patients whose data fell completely outside the range of age, histologic type, and performance status. ${ }^{11}$ A difference in survival with EPP was not evident. A Cox proportional hazard model that included 945 patients was reported to showed an association between surgical resection and survival, but there were also associations for histologic type, sex, smoking, asbestos exposure, and laterality. ${ }^{12}$ Residual confounding was likely. A more cautious 
analysis of the 945 patients showed no differences in survival those who underwent resection, opened and closed, and those turned down for surgery. ${ }^{13}$ Completing multimodality treatment is conditional on remaining alive and well enough; there may be a statistical association with longer survival, but attributing an effect to the surgical component may be illusory because only longer survivors are selected for, and can complete, the full sequence. ${ }^{14}$

EPP has a high rate of complications even in the most experienced hands. ${ }^{15}$ In a prospective study, EPP has been shown to have an adverse effect on quality of life from which the patients do not live long enough to recover. ${ }^{16}$ The patterns of recurrence have been well reported. ${ }^{8}$ It is the disease that is the problem, and the limitations on what can be achieved with surgery, not the skill or determination of the surgeons. Comparative studies have shown that patients who undergo less-morbid lung-sparing operations for malignant pleural mesothelioma (generically pleurectomy and decortication) have no worse survival than do those who undergo the more radical extrapleural pneumonectomy EPP. ${ }^{9,17}$ The finding that patients who undergo pleurectomy and decortication may live longer than those who undergo EPP does not mean that it is more effective in eradicating mesothelioma; it would be as logical to conclude that it is merely less harmful. When lesser treatment is associated with better outcomes, it is time to pause for thought, and it would be good if that pause allowed proper evaluation of treatments by means of randomized, controlled trials.

For patients suitable for 2 or more different surgical strategies, random assignment is the best way to allow potential confounding factors to be similarly distributed in the trial arms. ${ }^{18}$ Minimization ensures this is achieved. ${ }^{19}$ What is also important is that a formal and auditable prospective record be kept at each stage of the protocol so that intentionto-treat analysis can be performed. That is what prospective patients need to know, not what happened to "subsets of subsets of subsets" of patients not like them. ${ }^{20}$ What is also important is that professional trial centers be involved, working to the highest current standard. Data should be collected evenhandedly, and all findings and outcomes should be adjudicated objectively, wherever possible by someone blinded to the assigned treatment. Allowing us surgeons a free hand to adjudicate "macroscopic complete resection" is reminiscent of Damon Runyon's humorous description of a game of craps in 1930s New York. ${ }^{21}$ Rather than lose, Rusty Charley - "for he is a hard guy indeed"seizes the derby hat off the head of a much smaller player and throws the dice into the hat and announces that it's a 10. The unlucky loser who has to hand over a G-note says "Charley, do you make it the hard way?" Runyon translates, "two fives-which is the hard way to make a ten with the dice." A principle of clinical research is that impartial and preferably blinded "others" keep the record, but "Rusty Charley isn't a guy who is apt to let anybody question his word." Runyon, as a man who bet on the horses, knew the essentials of probability and the consequences of bias. ${ }^{21}$

The pathologist is the judge of completeness of resection by taking as many sections as necessary and looking at them under the microscope. The surgical boundaries are usually crossed. ${ }^{22}$ The phrase "macroscopic complete resection," which overrides that principle, has slipped into usage. It is possible that reducing the bulk of mesothelioma may allow chemotherapy or radiotherapy to gain purchase when they might not otherwise have done so, but it is at best a surrogate outcome. It is methodologically unsound that it is only the surgeon who can make the evaluation, looking into the thorax rather like Rusty Charley peering into the upturned derby hat.

Whatever clinical practice emerges from the present confused state should be based on trustworthy evidence, and where there is no evidence it would be good if surgeons could put their energy into obtaining it. Patients deserve to know up front what they can realistically expect to gain from surgery, where the evidence comes from, and what they are likely to pay for any gain in terms of pain and suffering. The best way to do that is with randomized, controlled trials. ${ }^{23}$

\section{References}

1. Treasure T, Utley M. Ten traps for the unwary in surgical series: a case study in mesothelioma reports. J Thorac Cardiovasc Surg. 2007;133:1414-8.

2. Treasure T, Lang-Lazdunski L, Waller D, Bliss JM, Tan C, Entwisle J, et al; MARS trialists. Extra-pleural pneumonectomy versus no extra-pleural pneumonectomy for patients with malignant pleural mesothelioma: clinical outcomes of the Mesothelioma and Radical Surgery (MARS) randomised feasibility study. Lancet Oncol. 2011;12:763-72.

3. Rintoul RC, Ritchie AJ, Edwards JG, Waller DA, Coonar AS, Bennett M, et al; MesoVATS Collaborators. Efficacy and cost of video-assisted thoracoscopic partial pleurectomy versus talc pleurodesis in patients with malignant pleural mesothelioma (MesoVATS): an open-label, randomised, controlled trial. Lancet. 2014;384:1118-27.

4. Neoadjuvant chemotherapy and extrapleural pneumonectomy (EPP) of malignant pleural mesothelioma (MPM) with or without hemithoracic radiotherapy: final results of the randomized multicenter phase II trial SAKK17/04. Abstract LBA37_PR. Ann Oncol. 2014;25(suppl 4):doi:http://dx.doi.org/10.1093/annonc/ mdu438.65.

5. Glasziou P, Chalmers I, Rawlins M, McCulloch P. When are randomised trials unnecessary? Picking signal from noise. BMJ. 2007;334:349-51.

6. Treasure T, Macbeth F. Fifteen years in the evaluation of extrapleural pneumonectomy: lessons to be learned. J Thorac Cardiovasc Surg. 2015;149:1382-3.

7. Rena $\mathrm{O}$, Casadio C. Lack of evidence in malignant pleural mesothelioma surgery. Interact Cardiovasc Thorac Surg. 2011;12:347-8.

8. Baldini EH, Richards WG, Gill RR, Goodman BM, Winfrey OK, Eisen HM, et al. Updated patterns of failure after multimodality therapy for malignant pleural mesothelioma. J Thorac Cardiovasc Surg. 2015;149:1374-81.

9. Batirel HF, Metintas M, Caglar HB, Ak G, Yumuk PF, Yildizeli B, et al. Adoption of pleurectomy and decortication for malignant pleural mesothelioma leads to similar survival outcomes as extrapleural pneumonectomy. J Thorac Cardiovasc Surg. 2016;151:478-84

10. Tilleman TR, Richards WG, Zellos L, Johnson BE, Jaklitsch MT, Mueller J, et al. Extrapleural pneumonectomy followed by intracavitary intraoperative hyperthermic cisplatin with pharmacologic cytoprotection for treatment of malignant 
pleural mesothelioma: a phase II prospective study. J Thorac Cardiovasc Surg. 2009;138:405-11.

11. Datta A, Smith R, Fiorentino F, Treasure T. Surgery in the treatment of malignant pleural mesothelioma: recruitment into trials should be the default position. Thorax. 2014;69:194-7

12. Flores RM, Zakowski M, Venkatraman E, Krug L, Rosenzweig K, Dycoco J, et al. Prognostic factors in the treatment of malignant pleural mesothelioma at a large tertiary referral center. J Thorac Oncol. 2007;2:957-65.

13. Utley M, Fiorentino F, Treasure T. Obtaining an upper estimate of the survival benefit associated with surgery for mesothelioma. Eur J Cardiothorac Surg. 2010;38:241-4

14. Treasure T, Mineo T, Ambrogi V, Fiorentino F. Survival is higher after repeat lung metastasectomy than after a first metastasectomy: too good to be true? J Thorac Cardiovasc Surg. 2015;149:1249-52

15. Sugarbaker DJ, Jaklitsch MT, Bueno R, Richards W, Lukanich J, Mentzer SJ, et al. Prevention, early detection, and management of complications after 328 consecutive extrapleural pneumonectomies. J Thorac Cardiovasc Surg. 2004; 128:138-46.

16. Rena O, Casadio C. Extrapleural pneumonectomy for early stage malignant pleural mesothelioma: a harmful procedure. Lung Cancer. 2012;77:151-5.
17. Flores RM, Pass HI, Seshan VE, Dycoco J, Zakowski M, Carbone M, et al. Extrapleural pneumonectomy versus pleurectomy/decortication in the surgical management of malignant pleural mesothelioma: results in 663 patients. $J$ Thorac Cardiovasc Surg. 2008;135:620-6. 626.e1-3.

18. Treasure T, Utley M. Assessing cardiothoracic surgery: practical examples. In: Boutron I, Ravaud P, Moher D, eds. Randomized clinical trials of nonpharmacological treatments. Boca Raton (FL): CRC Press; 2012 213-28.

19. Treasure T, MacRae KD. Minimisation: the platinum standard for trials? Randomisation doesn't guarantee similarity of groups; minimisation does. BMJ. 1998;317:362-3

20. Flores RM. The mesothelioma enigma. J Thorac Cardiovasc Surg. 2015;149 1548-9.

21. Runyon D. Blood pressure. Available at: http://fullreads.com/literature/bloodpressure/. Accessed October 16, 2015.

22. Hasani A, Alvarez JM, Wyatt JM, Bydder S, Millward M, Byrne M, et al Outcome for patients with malignant pleural mesothelioma referred for trimodality therapy in Western Australia. J Thorac Oncol. 2009;4:1010-6.

23. Evans HM. Should patients be allowed to veto their participation in clinical research? J Med Ethics. 2004;30:198-203.

Access to The Journal of Thoracic and Cardiovascular Surgery Online is reserved for print subscribers!

Full-text access to The Journal of Thoracic and Cardiovascular Surgery Online is available for all print subscribers. To activate your individual online subscription, please visit The Journal of Thoracic and Cardiovascular Surgery Online, point your browser to http://www.mosby.com/itcvs, follow the prompts to activate your online access, and follow the instructions. To activate your account, you will need your subscriber account number, which you can find on your mailing label (note: the number of digits in your subscriber account number varies from 6 to 10). See the example below in which the subscriber account number has been circled:

\section{Sample mailing label}

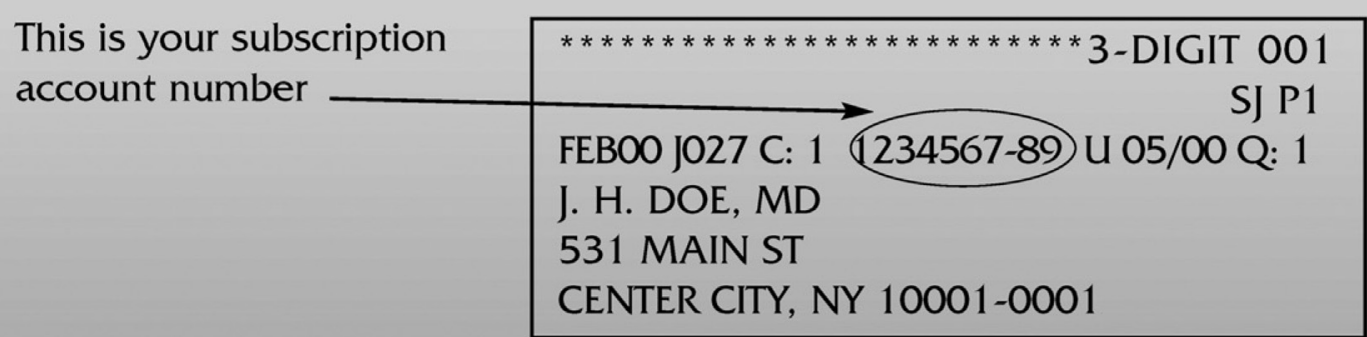

Personal subscriptions to The Journal of Thoracic and Cardiovascular Surgery Online are for individual use only and may not be transferred. Use of The Journal of Thoracic and Cardiovascular Surgery Online is subject to agreement to the terms and conditions as indicated online. 